\title{
A Contabilidade e a Administração
}

\section{Celso Magalhães}

$336.126: 35$

Estes comentários vêm a propósito de uma publicação do Sr. FloRINDo Focaccia, no Diário de Notícias, de 29-9-57, 3. a Seção, sob o título "Esquema Fundamental para a administração das Emprêsas", e por cujo subtítulo "Fayolismo e Usurpação", reclamava o articulista, para a ciência de sua profissão um lugar de predominância absoluta, que ela não tem e nem pode ter, em assuntos de administração em geral, exigindo ainda, seja proibido de emitir opinião, em qualquer assunto, quem não possuir título oficial idôneo .

Daí a estigmatização de FAYOL: meteu-se a falar em Contabilidade, quando era apenas um Engenheiro!...

E por ter feito escola, necessário se torna submeter a censura prévia ou drásticas sanções seus imitadores.

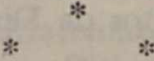

Não me canso de dizer que é o temperamento, e não a cultura política, quem faz um indivíduo democrata ou totalitário da direita ou da esquerda.

O traço característico da Democracia é a tolerância para opiniões e idéias alheias. Não importa fazer profissão de fé democrática, quando, por sistema, o indivíduo não tolera discrepância que afirma, nem permite que outros discutam matéria em que pretende pontificar.

Há muitos democratas cuja democracia consiste apenas em "permitir que outros pensem como êles".

O totalitarismo não se faz sentir sòmente nas idéies políticas; também há os totalitários nas Ciências, nas Artes e na Filosofia: basta contrariá-los e logo surgem, lança em riste, fulminando adversários e bradando por medidas que os silenciem.

Para êles, essa gente:

“... com um desembaraço impressionante e estimulados p⿶la ineficácia dos nossos órgãos fiscalizadores... já estão chegando ao ponto de, pùblicamente, em revista especializada, sem qualquer indicação legal quanto aos títulos de habilitação científica que estão na obrigação de possuir, dissertar a respeito... como se não existisse qualquer regulamentação profissional".

Ora, isso além de ser extremada intolerância, é pronunciada tendência inquisitorial, revelando desconhecimento entre debates de idéias e exercício 
de uma profissão, o que é imperdoável em quem se arroga o papel de mentor.

A cultura universitária não consiste apenas na posse de um título de Universidade, porém, - e muito mais - numa universalidade de conhecimentos.

Essa universalidade de conhecimentos é justamente o preparo geral e não especic lizado - em vários ramos do saber, o que permite ao indivíduo uma visão panorâmica das atividades mentais do homem, habilitando-o a se nãu tornar reacionário, fanático, intolerante.

Em matéria de s:ber não há compartimentos estanques: todos os conhecimentos se entrelaçam e, para bem dominar um de seus setores, mister se tcrna, não raro, penetrar na área em outros dominam.

Escrever numa revista técnica, fazer conferências, discutir assuntos especir lizados, apenas como estudioso, pesquisador, é muito diferente de exercer uma profissão.

Com efeito, há uma distância muito grande entre discutir questões de Direito, de Medicina, de Engenharia, de Contabilidade... e ser Advogado, Médico, Engenheiro, Contabilista...

E quantos leigos têm concorrido para o progresso das ciências e melhora da técnicé dos profissionais?

Imagine-se, num país culto, democrático, uma lei que proibisse a quem não fôsse Bacharel, Médico, Engenheiro, Contabilista... de escrever, discutir, emitir opinião a respeito de assuntos de Direito, de Medicina, de Engenharia, de Contabilidade!...

O pior é que essa lei teria de ser elaborada com o concurso de leigos, pois nés câmaras legislativas, a maioria não é de Bacharéis, de Médicos, de Engenheiros, de Contabilistas... e, assim teríamos que, na própria origem, a lei forçosamente seria fraudada.

E como iriam funcionar, mais tarde, as casas que legislam? Poderiam votar em essuntos de Direito, de Medicina, de Engenharia, de Contabilidade... Deputados, Senadores, Vereadores... que não fôssem Bacharéis, Médicos, Engenheiros, Contabilistas?

Teria de haver, positivamente, modificação profunda no regime político, porque o Estado democrático teria acabado.

Levada a teoric a seus extremos, ficariam os homens proibidos de falar, pois impossivel se torna sustentar uma palestra, ou manter um debate mesmo nãu acadêmico, sem penetrar em especialidades alheias.

Como iriam os Advogados exercer sua profissão se, na defesa de uma causa, lhes é por vêzes forçoso discutir os problemas mais complexos e estranhos à própria especialidade?

E os jornais? Que teriam êles para dizer, se o valor da imprensa está, justamente, na vcriedade dos assuntos que debate. Deveria haver um especialista para cada matéria?

E já está provado que são os especialistas oficialmente reconhecidos os que mais sabem a respeito da matéria de seus títulos? 
Não; felizmente nenhum homem culto defenderia semelhønte absurdo, verdađiciro crime contra a inteligência humana.

Isso deve ser sangue de "cristão novo", enjôo de marinheiro de primeira viagem, gesto de quem, colocado ainda na planície, não pode vislumbrar o soberbo panorama que se descortina do clto da montanha.

O fundamento da verdadeira cultura está na difusão de todos os conhecimentos. Os especialistas serão mais prestigiados, quanto mais o vulgo entender da especialidade de cada um. O hermetismo fica bem para as ciências ocultas, não para aquelas que se ministram nas universidades.

Ademais, o título, por si só, nada vale.

Aí estão os concursos do D.A.S.P., para atest de muitos portadores de pergaminhos, que melhor figura fariam se escondessem o anel que ostentam no dedo doutoral.

As ciências se dividem em principais e auxiliares. Nessa divisão, porém, ocorre a mesma coisa que se verifica com as ctividades específicas e gerais, em administração: tudo depende de ponto de vista.

Por exemplo, Contabilidade constitui atividade geral, mas também poderá constituir atividade específica: em relação a um sistema, é gerc1; em relação ao próprio órgão que a executa, porém, é específica.

Veja-se, por exemplo, o D.A.S.P., em matéria de Pessoal.

Assim com as Ciências: as Matemáticas constituem ciências princip̌is, mas não raro servem de auxiliares. Que seria a Física sem Matemáticas?

No mesmo caso está a Contabilidade em relação à Ciência da Administração: é auxiliar, como auxiliar é a Estatística, é a Psicotécnica, é a Economia, é o Direito...

Assim, a Contabilidade não pode, dentro da Administração, reivindicar para si o principal, quando seu papel, a despeito de ser importante, é subordinado.

O predomínio que the quer dar o Contabilista rebelado resulta, justamente, de sua falta de cultura universitárie, isto é, enciclopédia. E' isso que o impede de situar exatamente a ciência que aprendeu, no conjunto daquelas que não conhece.

Não se pode, entretanto, deixar a pretensão sem revide. Não que o ait:culista não tenha o direito de defender sua opinião, fazendo mesmo aquilo que condena nos outros, mas para que não se faça escola de idéias errôneas, inaceitáveis.

Digam o que disserem, ninguém estudou mais e melhor que FAyoL o papel do administrador nas emprêsas.

Os grandes Mestres que se lhe seguiram - e quantos houve - usando terminologia diferente, desdobrando o que êle sintetizou, sintetizando o que êle desdobrou, nada inovaram em seus princípios fundamentais. 
Assim, ainda hoje, as atividades que se processam dentro de uma emprêsa são as mesmas que êle indicou:

- técnicas;

- comerciais;

- financeiras;

- contábeis;

- de segurança;

- administrativas.

ÍMas, ao contrário do que se poderia pensar, FAyol não disse que as operações técnicas teriam de ser realizadas por técnicos; as comerciais, por titulados em comércio; as financeiras, por banqueiros; as contábeis, por contabilistas; as de segurança, por bacharéis e as administrativas, por diplomados em escolas de administração.

O que êle disse - e mui claramente - foi que os indivíduos, dentro de uma emprêsa -- todos, veja-se bem - seriam chamados ao desempenho daquelas atividades, em milo: ou menor grau.

FAyol chegnu mesno a determinar a capacidade que, na sua opinião, cada uma de tai's ıtividades exigiria dos diferentes trabalhadores - no sentido geral - dentro fa emprêsa. Assim, por exemplo:

Diretor:

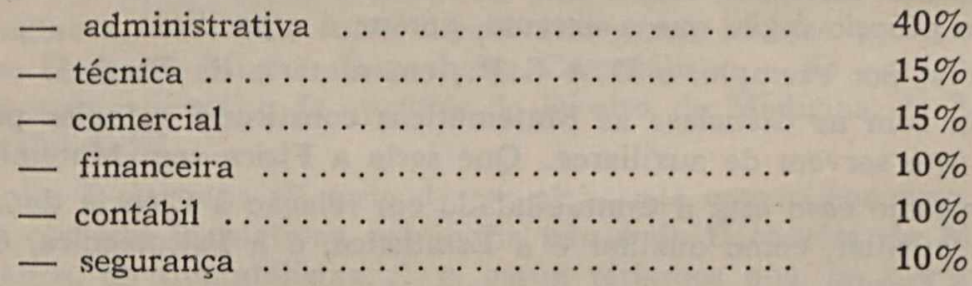

Isso significava, para êle, que um Diretor deveria estar mais capacitado a administrar que a intervir na elaboração dos produtos, nas compras e vendas, na procura e gestão dos capitais, nos cálculos e registros do que se processa dentro da emprésa, nos meios para proteger legal e materialmente seu patrimônio.

Mas, baixando na escala hierárquica, essa capacidade administrativa poderia ir diminuindo, outras poderiam desaparecer e outras ainda aumentar. A capacidade fincnceira, por exemplo, já não se faria necessária a partir de um Mestre de Oficina, nem a comercial para o operário, em que se exigiria, porém, o máximo de capacidade técnica:

Operário:

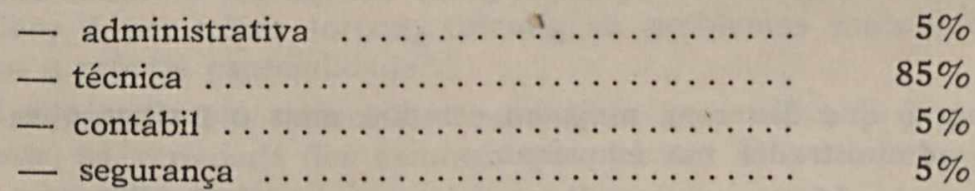

Ora, nenhum Contabilista admitiria que FAyol quisesse exigir que os operários de uma emprêsa fôssem todos titulados em Contabilidade, e isso 
porque FAyOL explicou o que se deveria entender por atividades contábeis: inventários, preço de custo, estatística, orçamentos, registros gerais...

Sim, para FAyol, o operário precisaria ter capacidade contábil porque, não rero, faz cálculos e registros.

$\mathrm{E}$ isso está perfeitamente certo, como estava ao tempo em que foi afirmado.

Poder-se-ia vislumbrar, talvez, uma impropriedade de têrmo, émbora valham os têrmos por sua definição e tenha FAYOL definido - como bom cartesiano que era - todos os seus. Todavia, é preciso não perder de vista que FAyOL foi um pioneiro e que, na época em que empreendeu seu estudo, várias das ciências auxiliares da Aciministração estavam ainda longe do prestígio que hoje desfrutam.

Mais razão teriam os Estatísticos de protestar, pela subordinação em que o têrmo usado por FAYOL thes colocou a ciência relativamente à Contabilidade.

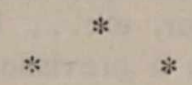

Quando FAYOL se refere a atividades administrativas, explica que elas dizem respeito:

— à previsão;

- à organização;

- ao comando;

- à coordenação;

- ao contrôle.

Não há um Técnico em Administração que negue o acêrto dessa classificação pois, para FAYoL:

- prever é perscrutar o futuro e traçar o programa de ação;

- organizar é construir o duplo organismo material e social da emprêsa;

- comandar é fazer funcionar o pessoal;

- coordenar é fazer com que se harmonizem as atividades;

- controlar é cuidar que tudo se passe de acôrdo com as normas estabelecidas.

Inegàveimente, êsse é o principal papel do Administrador, pelo que se conclui que o melhor Técnico não será, sòmente por isso, o melhor dirigente cie uma emprêsa ou repartição pública.

E verdade que o dirigente de um órgão também será chamado a intervir, embora em muito menor escala, nas outras atividades da emprêsa. Assim, não the podem ser estranhos assuntos tais como:

- fabricação e transformação (atividades técnicas);

- compra e venda (atividades comerciais);

- procura e gerência de capitais (atividades financeiras); 
- cálculos e registros (atividades contábeis);

- proteção de bens e pessoas (atividades de segurança).

Entretanto, quando se diz que o Administrador intervém em tôdas essas atıvidades, não se $\varepsilon$ firma que êle o faça diretamente e que precise, portanto, de ser um especialista em cada uma delas.

E por isso que as grandes emprêsas são departamentalizadas cabendo a um especialista em cada assunto a responsabilidade imediata por uma dessas atividades e por outras de natureza específica; é por isso que os chefes de nível superior são sempre assessorados por um verdadeiro estado-maior que lhes dá a base técnica para decidirem.

Quando se diz que o Administrador deve prever, orgєnizar, etc... não se desconhece - nem o desconhecia FAYOL - que existem Técnicos para cada uma dessas fases da atividade administrativa, de cujos serviços o Aan inistrador se valerá, como se valeria dos serviços de um Médico ou de un Advogacio, no momento exeto e para o fim específico. O que se quer e assim o quis FAyOL - é frisar que compete ao Chefe a iniciativa de mandar prever, mandar organizar, etc... bem como a oportunidade e o acè:to das decisões finais quanto à previsão, organização etc...

Ninguém chegeria ao absurdo de exigir do Presidente da República, por extraplo, o título de Contabilista, embora todos saibam que está êle intervindo constantemente em assuntos de contabilidade. O que se exige dêle é apenas que cunheça o valor dessa Ciência e saiba o que the poderá pedir no momento oportuno, louvando-se nos assessôres que possui.

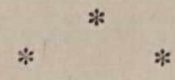

Cintrolar é ver se tudo está caminhøndo conforme os planos estabelecidos a fim de remover obstáculos que se opõem à consecução do objetivo.

Dentro de uma emprêsa ou repartição pública, o contrôle pode ser de caráter múltiplo. Por isso, dizer que êsse contrôle é "genuìnamente contábil" não passa de exagêro de profissional de visão estreita.

Com efeito, o contrôle pode ser:

- mecânico;

- estatístico;

- contábil;

- funcional;

- científico.

E mecânico, quando se faz mediante aparelhos especiais que bitolam peças ou fiscalizam operações.

E estatístico, quando feito através deı gráficos, tabelas e promédios.

E contábil, quando se refere à escrituração dos fatos e atos administrativos, $\varepsilon$ os balancetes e balanços.

E funcional, quando feito mediante exames do mesmo assunto em várias instânicias sucessivas, o que constitui os conhecidos "canais competentes".

E científico, quando realizado pelos diferentes laboratórios, de existência hoje indispensável nas grandes emprêsas. 
Os Contabilistas que conhecem, ręlmente, a Administração das Indústrias - e os há de grande valor - nunca defenderam, nem defenderiam idéia assim esdrúxula, de considerar o contrôle atividade "genuìnamente contábil".

$$
* *
$$

Tanto quanto o contrôle, é muito ousado dizer que a previsão administrativa é de caráter exclusivamente contábil.

Não há Administrador que desconheça a importância da Contabilidade na gestão de um patrimônio, mas daí a subestimar o valor de outras ciências das quais êle também se serve, a distância é grande.

Como o contrôle, também a previsão pode ser múltipla:

- orçamentária;

-. financeira;

- econômica;

- juridica;

- social.

Dentre tôdas elas, a Contabilidade é fator decisivo apen $s$ nas duas primeiras. Zom efeito, ninguém seria capaz de prever em matéria orçamentária, en matéria de procura e aplicação de capitais, sem precisas informiç̧ôes contábeis.

Na previsão econômica, porém, a Contabilidade cede a primazia à Estatística, fcis, antes que sôbre a técnica do Contદ bilista, é sôbre os conhecimenius ao Estatístico que repousa a análise econômica.

Nas cutras formas de previsão, a Contabilidade não figura, é totalmente desnecessária. E ninguém negará a importância da untevisão dos fatos jurídic'ss e sociais na administração da emprêsa, nem a que falência seria levada a indústria moderna se lhe faltasse o contrôle de laboratório.

Nâo ten portanto, créditc científico a idéia contida no subtítulo das notas quie comento.

$$
* \begin{gathered}
* \\
* \\
\text { SMO E USURPAÇÃO" }
\end{gathered}
$$

Não houve, nem há usurpação em afirmar que a Contabilidade não é, para o Administrédor, a ciência exclusiva da previsão e do contrôle; o ccntrário sim, é que seria verdadeira usurpação, pelo menosprêzo a setores de conhecimento sem os quais um sã e eficiente Administração se tornaria impossível, ainda que o Administrador dispusesse - o que nem sempre acontece - do auxílio, altamente estimável, de Contabilistas dedicados e competentes.

$$
* * *
$$

C progresso científico e culturel só é possível com debate livre de idéias e opiniốes. O papel dos doutos e especiclizados deve ser o de tolerância, deixandc talar aos leigos, aproveitando dêles o que de bom disserem, porque 
não raro o dizem, e corrigindo-os, quando se revelarem carecentes de orientação e esclarecimentos.

Relegando os argumentos do senso comum e da democracia cultural, há também que respeitar o regime jurídico em que vivemos, pois a própria Constituição dispõe, no seu art. $141, \S 5 .^{\circ}$, verbis:

"E' livr
censura..."

o que significa que qualquer um de nós poderá falar sôbre Direito, Medicina, Enpenhâria, Contabilidade..., dizendo as heresias que sua ignorância justificar, para raiva ou deleite dos mestres e especializados.

Agora, exercer a profissão de Advogado, de Médico, de Engenheiro, de Contacor... é coisa diferente, pois a mesma Constituição, ainda no citado artigo, § 14, dispõe, verbis:

"E' livre o exercício de qualquer profissão, observadas as condições de capacidade que a lei estabelecer".

Aí, então, é justo que caiba aos titulados o direito de reclamar dos órgãos de fiscalização profissional contra a prática ilegal da Advocacia, da Medicina, da Engenharia, da Contabilidade...

Entretanto, mais que isso, é preciso que os titulados se esforcem para valorizar as próprias atividades, atraindo para êles cada vez maior soma de prestígio profissional, mediante sucessivas e constantes demonstrações públicas de competência e correção de atitudes.

Nã: raro a intromissão de leigos em assuntos especializados decorre da fa:ıa de capacidade reconhecida naqueles que, pelos "títulos de habilitação científica" leveriam dominar tais assuntos. 